\title{
Regulation of Blood Flow to the Aortic Media in Dogs
}

\author{
Donald D. Heistad, Melvin L. Marcus, Edward G. Law, Mark L. Armstrong, \\ James C. Ehrhardt, and Francois M. AbBoud, Cardiovascular Division, \\ Department of Internal Medicine and Cardiovascular Center, University of Iowa \\ College of Medicine and Veterans Administration Hospital, Iowa City, Iowa 52242
}

A в S T R A C T Morphologic observations suggest that the inner layers of the thoracic aorta in man and dog are avascular and the outer layers have vasa vasorum. It appears that vasa vasorum are essential in the thoracic aorta because their interruption produces medial necrosis. These experiments provide the first measurements of blood flow through aortic vasa vasorum and examine physiologic regulation of that flow.

During control conditions the outer two-thirds of the media of the thoracic aorta received $10 \mathrm{ml} / \mathrm{min}$ per $100 \mathrm{~g}$ blood flow through vasa vasorum. Flow to the inner third of the aorta was $1 \mathrm{ml} / \mathrm{min}$ per $100 \mathrm{~g}$. Flow to both the inner and outer media of the abdominal aorta was less than $1 \mathrm{ml} / \mathrm{min}$ per $100 \mathrm{~g}$. Adenosine increased blood flow to vasa vasorum in the outer media of the thoracic aorta from 7 to $18 \mathrm{ml} / \mathrm{min}$ per $100 \mathrm{~g}$, but did not increase flow to the inner layers of the aorta. Hemorrhagic hypotension decreased flow in the outer media of the thoracic aorta from 14 to $2 \mathrm{ml} / \mathrm{min}$ per $100 \mathrm{~g}$. Acute hypertension failed to increase blood flow through vasa vasorum, as conductance decreased significantly.

These studies indicate that vasa vasorum provide a considerable amount of blood flow to the outer layers of the thoracic aorta. The vessels are responsive to physiologic stimuli because they dilate during infusion of adenosine and constrict during both hemorrhagic hypotension and acute hypertension. We speculate that the failure of blood flow to the aortic wall to increase during acute hypertension might, if it were sustained, contribute to aortic medial necrosis.

\section{INTRODUCTION}

The aorta may be nourished by diffusion of nutrients from the lumen of the vessel, by diffusion from adventitial vessels, or by blood flow through vascular channels in the media called vasa vasorum $(1,2)$. The aorta has important nutritional needs (3), but most of

Received for publication 13 October 1977 and in revised form 2 February 1978. its media is avascular. Geiringer (1) calculated that diffusion is sufficient to nourish the aorta when the thickness of avascular media is less than $0.5 \mathrm{~mm}$. When this "critical depth" is exceeded, nutrition of the media must be supplemented by vasa vasorum in the outer layers of the media. For example, in the thoracic aorta, which is $\sim 0.8-1.2 \mathrm{~mm}$ thick in dog and man, the inner half is almost avascular, but the outer half has vasa vasorum in the media $(1,2)$. In contrast, the media of the abdominal aorta is thinner than that of the thoracic aorta, and it is almost avascular (4).

Vasa vasorum may be important in at least three diseases of the aorta. First, Wolinsky and Glagov $(2,4)$ have suggested that the absence of vasa vasorum in the media of the abdominal aorta may explain in part the observation that the abdominal aorta is more severely involved by atherosclerosis than the thoracic aorta. They reported that because the abdominal aorta is about $0.7 \mathrm{~mm}$ thick in man, the "critical depth" is exceeded, and the absence of vasa vasorum may compromise the nutrition of the aortic media. Second, a study by Wilens et al. (5) suggests that aortic medial necrosis occurs after ligation of the intercostal arteries that give rise to vasa vasorum. Thus vasa vasorum are essential for the nourishment of the thoracic aorta, and they may be involved in the pathogenesis of aortic medial necrosis and dissecting aneurysm. Third, onionskin-like stenosis of vasa vasorum often occurs in Takayasu's "pulseless" disease (6) and may contribute to the progressive vascular changes.

Previous studies of vasa vasorum have been limited to morphologic observations. There have been no measurements of blood flow to the wall of the aorta and no studies on the physiologic regulation of blood flow through vasa vasorum. In these experiments we have used microspheres to provide the first measurements of blood flow through vasa vasorum. The purposes of the study were, first, to evaluate some of the concepts about these vessels which have evolved from morphologic evidence and, second, to determine whether blood flow through vasa vasorum is affected by several physiologic stimuli. 


\section{METHODS}

Animal preparation. 17 unanesthetized mongrel dogs weighing 20-28 kg were studied. Approximately $1 \mathrm{wk}$ before the experiment, cannulae were implanted in the left atrial appendage for injection of microspheres and in the internal mammary artery for withdrawal of blood samples. During the experiments the dogs were unsedated and stood quietly, supported by a harness under the abdomen. Arterial pressure was measured with transducers centered at mid-chest.

In 21 other experiments, dogs weighing $18-31 \mathrm{~kg}$ were anesthetized with intravenous chloralose $(50 \mathrm{mg} / \mathrm{kg})$ and urethane $(500 \mathrm{mg} / \mathrm{kg})$, paralyzed with decamethonium bromide $(0.3 \mathrm{mg} / \mathrm{kg})$, and ventilated artificially. Cannulae were placed in the left atrium for injection of microspheres, in a brachial and carotid artery for withdrawal of blood samples, and in the other brachial artery for measurement of pressure.

Morphologic studies. To visualize vasa vasorum, a catheter was inserted retrogradely into an intercostal artery of five anesthetized dogs. Colloidal carbon was infused into the artery for $\sim 6 \mathrm{~s}$ and the dog was quickly killed. A segment of the descending aorta, with the intercostal artery, was removed. The aorta was fixed in formalin, dehydrated by graded alcohols, and made translucent by methyl salicylate and benzyl benzoate clearing (7). Very thick sections, $\sim 1 \mathrm{~mm}$ thick, were examined microscopically.

Measurement of flow. Blood flow through vasa vasorum was measured with labeled microspheres. The microsphere technique is used routinely in our laboratory for measuring blood flow to the brain (8) and heart (9), and our experimental approach has been described in detail.

To measure blood flow through vasa vasorum, we injected between 3 and 12 million microspheres, 9 or $15 \mu \mathrm{m}$ in diam., labeled with ${ }^{46} \mathrm{Sc},{ }^{125} \mathrm{Sc},{ }^{85} \mathrm{Sr}$, or ${ }^{141} \mathrm{Ce}$ into the left atrium. Before injection, the vial containing microspheres and one drop of Tween 80 (Atlas Chemical Industries, Inc., Wilmington, Del.) was agitated vigorously for $5 \mathrm{~min}$. Microscopic examination showed that $98 \%$ of the spheres were dispersed. Occasional groups of three to five spheres were observed. The microspheres were injected slowly over a period of $20 \mathrm{~s}$ and the cannula was then flushed with $5 \mathrm{ml}$ of $37^{\circ} \mathrm{C}$ saline during the subsequent $30 \mathrm{~s}$. Beginning $30 \mathrm{~s}$ before microsphere injection and continuing until $3 \mathrm{~min}$ after injection, reference blood samples were withdrawn from the brachial and carotid arteries at $2.06 \mathrm{ml} / \mathrm{min}$ with a Harvard pump (Harvard Apparatus Co., Millis, Mass.). Blood samples were collected from the tubing as well as withdrawal syringes. Each syringe and its tubing was flushed twice with $5 \mathrm{ml}$ of saline, and the diluent was saved to ensure that nearly all microspheres were recovered.

At the end of each study, the animal was killed and the vessels were excised. Segments of ascending and descending aorta were removed. The adventitia was stripped from the samples with a dissecting microscope. Histologic examination indicated that essentially all of the adventitia was removed. The aortic media was then split into inner layers (approximately one-third of the wall) and outer layers (approximately two-thirds of the wall). Tissue samples weighed from 0.6 to $2.8 \mathrm{~g}$.

A segment of abdominal aorta was also removed. The adventitia is more difficult to separate from the media in the abdominal aorta than in the thoracic aorta. In most experiments the adventitia was not removed from the abdominal aorta, and the values which we report are for "intact" abdominal aorta (Tables I-III). We also obtained samples from the inner onethird of the media of the abdominal aorta. In one study (Table IV) the adventitia was removed from the abdominal aorta. Microscopic examination indicated that virtually all of the adventitia was removed.
The tissues were weighed, placed in plastic tubes, and counted for $10 \mathrm{~min}$ in a 3-in, well-type gamma counter. Reference blood samples were divided into aliquots so that their counting geometry was similar to that of the tissue samples. The energy windows were $700-1,500 \mathrm{keV}\left({ }^{46} \mathrm{Sc}\right), 20-50 \mathrm{keV}$ $\left({ }^{125} \mathrm{I}\right), 400-600 \mathrm{keV}\left({ }^{85} \mathrm{Sr}\right)$, and $125-175 \mathrm{keV}\left({ }^{141} \mathrm{Ce}\right)$. The isotope separation was performed according to standard techniques (10). Output from the gamma counter was punched on paper tape and processed in a PDP-11 computer. Blood flow through vasa vasorum was calculated utilizing the formula: $\mathrm{CV} \times 100 \times \mathrm{RBF} / \mathrm{CR}=$ vasa vasorum blood flow in $\mathrm{ml} / \mathrm{min}$ per $100 \mathrm{~g}$ of aorta, where $\mathrm{CV}=$ counts per gram of aortic sample, RBF = reference blood flow (rate of withdrawal of blood samples from arteries in milliliters per minute), and $C R=$ total counts in reference arterial blood. When two reference blood samples were taken, the counts were averaged.

Statistical analysis was performed by analysis of variance and Tukey's test (11).

Measurement with 9-, 15-, and 25- $\mu m$ spheres. It was important to determine whether arteriovenous shunts are present in vasa vasorum. If shunts were present small microspheres (e.g., $9 \mu \mathrm{m}$ diam) would not be trapped in the vessel and would therefore underestimate flow. If shunts were not present, simultaneous injection of small $(9 \mu \mathrm{m})$ and larger $(25$ $\mu \mathrm{m})$ microspheres should give similar values for blood flow.

Eight anesthetized dogs were studied. Microspheres of $9 \pm 1$, $15 \pm 3$, and $25 \pm 5 \mu \mathrm{m}$ in diameter, labeled with ${ }^{46} \mathrm{Sc},{ }^{125} \mathrm{I}$, and ${ }^{85} \mathrm{Sr}$, respectively, were used. Between 1 and 12 million microspheres of each size were mixed together and injected simultaneously into the left atrium. In five dogs, microspheres were injected during normal conditions. In three other dogs, microspheres were injected 3-5 min after starting an intravenous infusion of adenosine (4.7 $\mu \mathrm{M} / \mathrm{kg}$ per min). Adenosine was infused to determine whether shunting through vasa vasorum occurs during a potent vasodilator stimulus.

After these initial studies were completed, subsequent experiments were performed in unanesthetized dogs whenever possible. Effects of intravenous adenosine and hemorrhage were examined in unanesthetized dogs. Effects of hypertension, however, were examined in anesthetized dogs because the studies required clamping of the aorta. Comparison of results obtained during control periods in unanesthetized and anesthetized dogs suggest that anesthesia does not have substantial effects on blood flow through vasa vasorum.

Effects of adenosine. Nine unanesthetized dogs were studied. A catheter was inserted into the brachial vein, with xylocaine local anesthesia, for infusion of adenosine. Microspheres were injected three times during each study: during two control periods (to evaluate the reproducibility of the method) and 3-5 min after starting an intravenous infusion of adenosine (4.7 $\mu \mathrm{M} / \mathrm{kg}$ per min). We injected $9-\mu \mathrm{m}$ spheres labeled with ${ }^{85} \mathrm{Sr}$ or ${ }^{46} \mathrm{Sc}$ and $15-\mu \mathrm{m}$ spheres labeled with ${ }^{125} \mathrm{I}$. The order in which the three isotopes were injected was randomized. Conductance was calculated by dividing blood flow by mean arterial pressure.

Effects of hypotension. Eight unanesthetized dogs were studied. Microspheres were injected during control period and during three levels of hypotension, produced by hemorrhage. We attempted to achieve mean arterial pressures of 80,55 , and $40 \mathrm{~mm} \mathrm{Hg}$ and to maintain each level of pressure for about 5 min before injecting microspheres. In some experiments the desired level of arterial pressure was not achieved at the time the microspheres were injected, and the values were excluded. We injected $15-\mu \mathrm{m}$ spheres labeled with ${ }^{85} \mathrm{Sr}$, ${ }^{46} \mathrm{Sc},{ }^{125} \mathrm{I}$, or ${ }^{141} \mathrm{Ce}$.

Effects of acute hypertension. Nine anesthetized dogs were studied. Two methods were used to produce a similar level of hypertension: intravenous infusion of norepineph- 


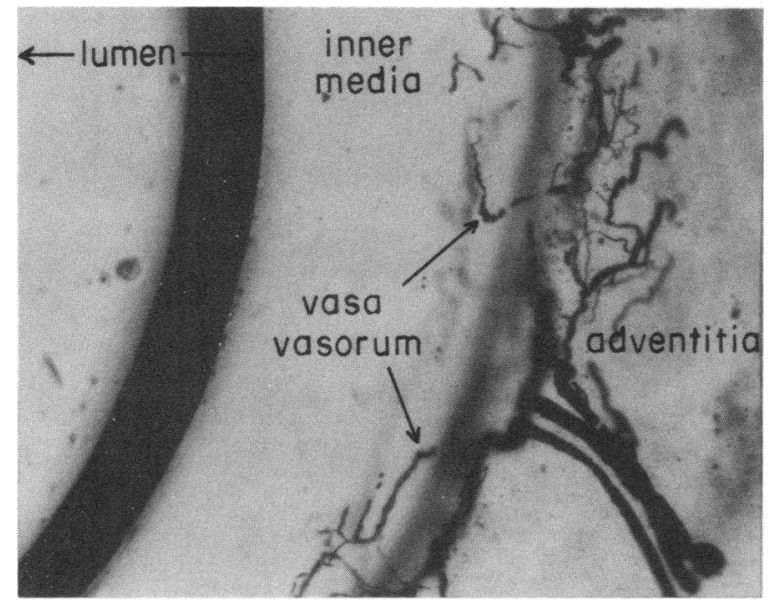

FIGURE 1 Thick section ( $1 \mathrm{~mm}$ ) of descending thoracic aorta. Large vessels are present in the adventitia and small vasa vasorum penetrate the media of the aorta. The inner half of the media appears to be avascular. The section was cleared by Spalteholz method (Magnification $\times 100$ ).

rine, and occlusion of the aorta at the level of the diaphragm. With the two methods, we were able to determine effects of hypertension in the presence and absence of direct vasoconstrictor effects of norepinephrine. Measurements were made during control period, during aortic occlusion, and during intravenous infusion of norepinephrine. The aorta was occluded with a clamp immediately cephalad to the diaphragm, $\sim 2$ in below the segment of descending aorta which was later removed for determination of flow. The clamp distorted the aorta for less than $1 \mathrm{in}$, did not appear to distort the more proximal descending aorta, and clearly did not distort the ascending aorta. The mean systemic arterial pressure rose $\sim 30-$ $35 \%$ during aortic occlusion and during infusion of 25-50 $\mu \mathrm{g} / \mathrm{min}$ norepinephrine and remained at this level for $10 \mathrm{~min}$ before the microspheres were injected. The order of the control period and interventions and the order in which the isotopes were injected were randomized.

It was possible that the effects on flow to the thoracic aorta during aortic occlusion might be produced, not by the increase in arterial pressure in the cephalad half of the body, but by the decrease in pressure in the caudad half of the body. The renal ischemia which occurs during aortic occlusion might lead to renin release and angiotensin-induced constriction of vasa vasorum. To assess this possibility, four anesthetized dogs were prepared as above, and both renal pedicles (including renal arteries and veins) were ligated before flow measurements were obtained. Ligation of the renal pedicles was performed to minimize release of renin into the systemic circulation during aortic occlusion. Microspheres were injected during a control period and during aortic occlusion. The order of these two injections was randomized.

\section{RESULTS}

Morphology. After injection of colloidal carbon into an intercostal artery, large vessels were seen in the adventitia of all dogs and small vasa vasorum were observed penetrating the media of the aorta (Fig. 1). The internal diameter of the medial vasa vasorum was less than $60 \mu \mathrm{m}$. The inner half of the media appeared to be avascular.

Evaluation of the method. Blood flow measured with microspheres 9,15 , and $25 \mu \mathrm{m}$ in diameter was similar during both control conditions and during vasodilation induced by adenosine (Table I). Specifically, blood flow measured with small microspheres (9 and $15 \mu \mathrm{m}$ diam) was not significantly less than flow measured simultaneously with larger microspheres $(25 \mu \mathrm{m}$ diam). This finding suggests that small microspheres do not shunt through arteriovenous anastomoses and do not underestimate blood flow.

We evaluated the reproducibility of the results over a period of 15-30 min during two consecutive injections of microspheres during control conditions (Table II). There was a high correlation $(r=0.89)$ between the estimates of flow to the thoracic aorta during the two control periods.

Distribution of vasa vasorum in the aorta. During control conditions, the average blood flow through vasa vasorum in the outer two-thirds of the media of the as-

TABLE I

Blood Flow to Aortic Media Measured with 9-, 15-, and 25- $\mu m$ Microspheres*

\begin{tabular}{|c|c|c|c|c|c|c|}
\hline & \multicolumn{3}{|c|}{ Control (5 dogs) } & \multicolumn{3}{|c|}{ Adenosine (3 dogs) } \\
\hline & $9 \mu \mathrm{m}$ & $15 \mu \mathrm{m}$ & $25 \mu \mathrm{m}$ & $9 \mu \mathrm{m}$ & $15 \mu \mathrm{m}$ & $25 \mu \mathrm{m}$ \\
\hline \multicolumn{7}{|c|}{ Ascending aorta media } \\
\hline Inner layers & $1.7 \pm 0.9$ & $1.5 \pm 0.4$ & $1.1 \pm 0.4$ & $0.9 \pm 0.6$ & $1.8 \pm 1.4$ & $1.0 \pm 0.8$ \\
\hline Outer layers & $5.6 \pm 0.8$ & $7.5 \pm 1.6$ & $5.7 \pm 1.1$ & $13.0 \pm 3.1$ & $20.0 \pm 4.3$ & $16.3 \pm 6.4$ \\
\hline \multicolumn{7}{|c|}{ Descending aorta media } \\
\hline Inner layers & $0.9 \pm 0.5$ & $1.0 \pm 0.9$ & $1.8 \pm 1.2$ & $0.4 \pm 0.4$ & $0.8 \pm 0.5$ & $0.4 \pm 0.2$ \\
\hline Outer layers & $7.8 \pm 2.2$ & $10.0 \pm 3.2$ & $8.7 \pm 1.7$ & $21.5 \pm 5.5$ & $27.8 \pm 9.6$ & $25.4 \pm 8.8$ \\
\hline \multicolumn{7}{|c|}{ Abdominal aorta } \\
\hline Inner media & $0.01 \pm 0.00$ & $0.10 \pm 0.03$ & $0.2 \pm 0.1$ & \multirow{2}{*}{\multicolumn{3}{|c|}{$\begin{array}{l}\text { Not obtained } \\
\text { Not obtained }\end{array}$}} \\
\hline Intact & $2.7 \pm 0.2$ & $2.5 \pm 0.4$ & $3.1 \pm 0.5$ & & & \\
\hline
\end{tabular}

* Values are expressed as milliliters per minute per $100 \mathrm{~g}$ vessel (mean $\pm \mathrm{SE}$ ).

\$ Aortic media was split into inner layers (inner one-third) and outer layers (outer two-thirds). Adventitia was removed from thoracic aorta but not the abdominal aorta. 
TABLE II

Reproducibility of Method and Effect of Intravenous Adenosine*

\begin{tabular}{|c|c|c|c|}
\hline & Control 1 & Control 2 & Adenosine \\
\hline Arterial pressure, $\mathrm{mm} \mathrm{Hg}$ & $99 \pm 4.4$ & $108 \pm 2.5$ & $71 \pm 5.8 \ddagger$ \\
\hline \multicolumn{4}{|l|}{ Blood flow, $\mathrm{ml} / \mathrm{min}$ per $100 \mathrm{~g}$} \\
\hline \multicolumn{4}{|l|}{ Ascending aorta media } \\
\hline Inner layers & $1.4 \pm 0.6$ & $1.7 \pm 0.5$ & $1.0 \pm 0.4$ \\
\hline Outer layers & $6.1 \pm 1.4$ & $6.6 \pm 0.9$ & $14.9 \pm 2.5$ \\
\hline \multicolumn{4}{|l|}{ Descending aorta media } \\
\hline Inner layers & $0.9 \pm 0.4$ & $1.0 \pm 0.4$ & $1.6 \pm 0.7$ \\
\hline Outer layers & $7.2 \pm 1.6$ & $6.8 \pm 1.0$ & $20.3 \pm 3.2 \ddagger$ \\
\hline \multicolumn{4}{|l|}{ Abdominal aorta } \\
\hline Inner media & $0.5 \pm 0.2$ & $0.8 \pm 0.4$ & $1.0 \pm 0.6$ \\
\hline Intact & $3.1 \pm 0.5$ & $3.8 \pm 0.5$ & $6.4 \pm 1.0 \ddagger$ \\
\hline \multicolumn{4}{|c|}{ Conductance, $\mathrm{ml} / \mathrm{min}$ per $100 \mathrm{~g}$ per $\mathrm{mm} \mathrm{Hg}$} \\
\hline Ascending aorta (outer layers) & $6.2 \pm 1.1$ & $6.8 \pm 1.4$ & $20.1 \pm 4.1 \neq$ \\
\hline Descending aorta (outer layers) & $7.8 \pm 1.4$ & $6.4 \pm 1.0$ & $31.3 \pm 5.0 \ddagger$ \\
\hline Number of dogs & 9 & 7 & 9 \\
\hline
\end{tabular}

* Values are expressed as mean $\pm \mathrm{SE}$.

Indicates value is significantly different $(P<0.05)$ from control.

cending and descending thoracic aorta of all dogs was $10 \mathrm{ml} / \mathrm{min}$ per $100 \mathrm{~g}$ blood flow (Tables I-IV). Blood flow to the inner third of the media of the thoracic aorta was only $1 \mathrm{ml} / \mathrm{min}$ per $100 \mathrm{~g}$.

Blood flow to the full thickness of the abdominal aorta including adventitia was $4 \mathrm{ml} / \mathrm{min}$ per $100 \mathrm{~g}$ (Tables I-III). Flow to the inner third of abdominal aorta was less than $1 \mathrm{ml} / \mathrm{min}$ per $100 \mathrm{~g}$. When the adventitia was removed, flow to the outer media of the abdominal aorta was less than $1 \mathrm{ml} / \mathrm{min}$ per $100 \mathrm{~g}$ (Table IV).

Effects of adenosine. Adenosine increased blood flow and conductance in vasa vasorum in the outer layers of the media of the thoracic aorta (Table II). Despite infusion of adenosine, the inner layers of the aorta received minimal blood flow through vasa vasorum.

Effects of hemorrhage. During hemorrhagic hypotension there was a significant decrease in blood flow and conductance in vasa vasorum in the media of the outer layers of the thoracic aorta (Table III).

Effects of hypertension. Despite a significant increase in arterial pressure during aortic occlusion, blood flow through vasa vasorum in the thoracic aorta decreased (Table IV). Conductance of vasa vasorum

TABLE III

Effect of Hemorrhagic Hypotension*

\begin{tabular}{|c|c|c|c|c|}
\hline & Control & Hypotension $_{1}$ & Hypotension $_{2}$ & Hypotension $_{3}$ \\
\hline Arterial pressure, $\mathrm{mm} \mathrm{Hg}$ & $110 \pm 3.0$ & $78 \pm 6.4$ & $54 \pm 5.7$ & $41 \pm 3.5$ \\
\hline \multicolumn{5}{|l|}{ Blood flow, $\mathrm{ml} / \mathrm{min}$ per $100 \mathrm{~g}$} \\
\hline \multicolumn{5}{|l|}{ Ascending aorta media } \\
\hline Inner layers & $0.7 \pm 0.3$ & $0.8 \pm 0.4$ & $0.5 \pm 0.3$ & $0.2 \pm 0.2$ \\
\hline Outer layers & $14.0 \pm 1.5$ & $6.2 \pm 0.7 \ddagger$ & $3.0 \pm 0.5 \ddagger$ & $2.1 \pm 0.6 \ddagger$ \\
\hline \multicolumn{5}{|l|}{ Descending aorta media } \\
\hline Inner layers & $0.5 \pm 0.1$ & $0.5 \pm 0.3$ & $0.1 \pm 0.05$ & $0.1 \pm 0.02$ \\
\hline Outer layers & $15.1 \pm 3.5$ & $7.0 \pm 0.5$ & $3.6 \pm 0.5 \ddagger$ & $1.9 \pm 0.4 \ddagger$ \\
\hline \multicolumn{5}{|l|}{ Abdominal aorta } \\
\hline Inner media & $0.9 \pm 0.5$ & $0.2 \pm 0.2$ & $0.1 \pm 0.1$ & $0.03 \pm 0.01$ \\
\hline Intact & $7.4 \pm 1.2$ & $1.9 \pm 0.7 \ddagger$ & $0.8 \pm 0.2 \ddagger$ & $1.2 \pm 0.4 \ddagger$ \\
\hline \multicolumn{5}{|c|}{ Conductance, $\mathrm{ml} / \mathrm{min}$ per $100 \mathrm{~g}$ per $\mathrm{mm} \mathrm{Hg}$} \\
\hline Ascending aorta (outer layers) & $12.8 \pm 1.4$ & $8.2 \pm 1.2$ & $5.6 \pm 1.0 \ddagger$ & $5.0 \pm 1.1 \ddagger$ \\
\hline Descending aorta (outer layers) & $13.7 \pm 3.1$ & $9.1 \pm 0.9$ & $6.7 \pm 0.9$ & $4.9 \pm 1.4 \ddagger$ \\
\hline Number of dogs & 8 & 5 & 4 & 6 \\
\hline
\end{tabular}

* Values are expressed as mean $\pm \mathrm{SE}$.

$\$$ Indicates value is significantly different from control $(P<0.05)$. 
TABLE IV

Effect of Hypertension Induced by Aortic Occlusion or Intravenous Norepinephrine*

\begin{tabular}{lccc}
\hline & Control & Aortic occlusion & Norepinephrine \\
\hline $\begin{array}{l}\text { Arterial pressure, mm Hg } \\
\text { Blood flow, ml/min per 100 }\end{array}$ & $98 \pm 6$ & $134 \pm 5$ & $131 \pm 4$ \\
$\quad$ Ascending aorta media & & & \\
$\quad$ Inner layers & $0.7 \pm 0.2$ & $0.8 \pm 0.4$ & $0.9 \pm 0.3$ \\
$\quad$ Outer layers & $8.6 \pm 0.9$ & $6.9 \pm 0.8 \ddagger$ & $8.0 \pm 0.8$ \\
$\quad \begin{array}{l}\text { Descending aorta media } \\
\quad \text { Inner layers }\end{array}$ & $0.2 \pm 0.1$ & $0.8 \pm 0.6$ & $0.3 \pm 0.2$ \\
$\quad$ Outer layers & $9.7 \pm 0.3$ & $6.2 \pm 1.1 \ddagger$ & $9.3 \pm 1.0 \S$ \\
$\quad \begin{array}{l}\text { Abdominal aorta media } \\
\quad \text { Inner layers }\end{array}$ & $0.5 \pm 0.3$ & $\|$ & $0.1 \pm 0.1$ \\
$\quad$ Outer layers & $0.8 \pm 0.4$ & 11 & $0.9 \pm 0.3$ \\
Conductance, ml/min per 100 g per mm Hg & & & \\
$\quad$ Ascending aorta (outer layers) & $8.8 \pm 1.2$ & $5.2 \pm 0.7 \ddagger$ & $6.2 \pm 0.8 \ddagger$ \\
Descending aorta (outer layers) & $9.8 \pm 1.7$ & $4.8 \pm 0.9 \ddagger$ & $7.1 \pm 0.9$ \\
\hline
\end{tabular}

* Values were obtained in nine dogs; vessels were dissected as indicated in legend to Table I except the adventitia was removed from the outer layers of the media of the abdominal aorta. $\ddagger$ Indicates values were significantly different $(P<0.05)$ from control value.

$\S$ Indicates values were significantly different from aortic occlusion.

"Blood flow to the abdominal aorta below the aortic clamp was $0.1 \pm 0.1 \mathrm{ml} / \mathrm{min}$ per $100 \mathrm{~g}$ during occlusion of the aorta.

decreased during aortic occlusion. During hypertension produced by intravenous infusion of norepinephrine, blood flow through vasa vasorum was unchanged and conductance decreased significantly in the ascending aorta.

In four dogs both renal arteries and veins were ligated before flow measurements were obtained. Aortic occlusion increased mean arterial pressure from $110 \pm$ 11 (mean $\pm \mathrm{SE}$ ) to $152 \pm 5 \mathrm{~mm} \mathrm{Hg}$ but did not increase blood flow through vasa vasorum. In all four dogs conductance decreased during aortic occlusion in the ascending aorta (from $7.6 \pm 2.7$ to $5.9 \pm 2.2 ; P<0.05$ ) and the descending aorta (from $11.4 \pm 2.9$ to $6.5 \pm 1.8 ; P$ $<0.05)$.

\section{DISCUSSION}

We have described a method which has made feasible the first measurements of blood flow through vasa vasorum. The studies indicate that vasa vasorum provide a considerable amount of blood flow to the outer layers of the thoracic aorta. The vessels are responsive to physiologic stimuli: they dilate during infusion of adenosine and constrict during hemorrhagic hypotension. Transient increases in perfusion pressure during acute hypertension do not increase blood flow through vasa vasorum.

Several aspects of this study should be considered: (a) the method used to measure blood flow through vasa vasorum, $(b)$ mechanisms by which the wall of blood vessels are nourished, $(c)$ responsiveness of vasa vasorum to dilator and constrictor stimuli, and $(d)$ effects of hypertension on blood flow through vasa vasorum.

Measurement of blood flow through vasa vasorum. Labeled microspheres have been used to measure blood flow to many organs (12). Several assumptions should be examined concerning the use of microspheres in measuring flow to vessel walls.

One assumption is that the microspheres are trapped in one circulation through the tissue, and that they do not pass through arteriovenous shunts and thereby underestimate flow. We found that large $(25 \mu \mathrm{m})$ and small $(9 \mu \mathrm{m})$ microspheres give the same values for blood flow through vasa vasorum, during normal conditions and during vasodilation produced by adenosine. This finding suggests that small microspheres do not pass through arteriovenous shunts. Another method for detecting shunting is to determine whether there are microspheres in venous blood from an organ $(13,14)$. However, we have not been able to collect the venous effluent from vasa vasorum. With this reservation, it nevertheless seems reasonable to conclude that small microspheres (9 and $15 \mu \mathrm{m}$ diam) do not pass through shunts and can be used to measure blood flow in vessel walls.

A second assumption is that the number of capillaries and arterioles occluded by the microspheres is not sufficient to have important effects on organ blood flow. During two consecutive control measurements (Table II) there was no evidence for lower blood flow through vasa vasorum during the second measurement. Fur- 
thermore we were able to detect both constrictor and dilator responses of vasa vasorum, which suggests that the microspheres did not interfere with the responsiveness of these vessels.

A third assumption is that microspheres are evenly distributed in the blood. This assumption is particularly important in determination of distribution of blood flow within an organ. There is good evidence for maldistribution of large $(50 \mu \mathrm{m})$ microspheres in the heart (14) and brain (13). We have used smaller microspheres to minimize this potential limitation.

Nourishment of vessel walls. The aortic wall has modest oxygen requirements. Estimates of oxygen consumption of the aorta range from 0.15 to $0.75 \mathrm{ml}$ $\mathrm{O}_{2} /$ min per $100 \mathrm{~g}$ wet wt (3). These values may be lower in large mammals. For comparison, the oxygen requirements of resting skeletal muscle are $\sim 0.15 \mathrm{ml} /$ min per $100 \mathrm{~g}$, and for contracting myocardium the requirements are $\sim 8 \mathrm{ml} / \mathrm{min}$ per $100 \mathrm{~g}$.

The vessel wall may be nourished by diffusion from the lumen, by diffusion from adventitial vessels, or by blood flow through vasa vasorum in the media. The current concept, which is that all three sources are important, is supported by the limited evidence described below.

Oxygen availability in the femoral artery of dogs has been measured by a polarographic method (15). Oxygen levels are highest in the outer layers of the vessel and decrease as the electrode is advanced toward the lumen. These results suggest that the major source of oxygen in this vessel is by diffusion from adventitial vessels or through blood flow through intramural vasa vasorum. Disruption of adventitial vessels and intramural vasa vasorum by autotransplantation of the femoral artery reverses the oxygen gradient: after autotransplantation, oxygen levels are highest in the inner layers of the vessel (15). These results suggest that diffusion of oxygen from the lumen is also an important source of nutrition.

Vasa vasorum are present in the outer layers of the media of the thoracic aorta in humans, dogs, and other large mammals $(1,2,4,5)$. The inner layers of the aorta are avascular and must be nourished by diffusion. Wolinsky and Glagov $(2,4)$ have related the depth of the avascular zone to the number of concentric fibromuscular layers they termed lamellar units. They found that vasa vasorum are demonstrable only in species with more than 29 lamellar units and that the vasa vasorum are present only in the media outside the innermost 29 units $(2,4)$. The thoracic aorta of man and dog have more than 29 lamellar units and have vasa vasorum in the outer layers of the media although the abdominal aorta in these species has only 28 lamellar units and does not have medial vasa vasorum (4).

Based on the morphologic evidence described above and from Fig. 1, we expected to find blood flow through vasa vasorum in the media of the outer layers of the thoracic aorta with little or no flow to the inner layers. The measurements confirmed this prediction (Fig. 2). There is a moderate amount of flow through medial vasa vasorum in the outer thoracic aorta, but the inner layers have virtually no flow. When the adventitia is included in the tissue sample, the abdominal aorta has some blood flow (Tables I-III), but when the adventitia is removed there is minimal flow (Table IV). It appears that the entire thickness of media of the abdominal aorta is almost avascular. These findings strongly support the concept, previously based only on morphologic evidence, that the media of the inner layers of the thoracic aorta and the entire abdominal aorta is avascular and nourished by diffusion.

Responsiveness of vasa vasorum to dilator and constrictor stimuli. The observations that vasa vasorum dilate significantly during adenosine and constrict during hemorrhagic hypotension indicate that vasa vasorum are not passive channels in the wall of the aorta. In addition to the physiologic evidence for responsiveness of vasa vasorum, we have observed in electron micrographs ${ }^{1}$ a layer of smooth muscle around the vasa. The smooth muscle is oriented in relation to the vasa rather than the aortic media, and provides an anatomic basis for active regulation of blood flow through vasa vasorum.

Adenosine increased conductance of vasa vasorum. The primary mechanism for the increase in conductance during infusion of adenosine probably is a direct effect of the drug on the smooth muscle of the vasa vasorum, producing active vasodilation. The contribution of reflex and humoral mechanisms during hemorrhagic hypotension and adenosine, and the relative importance of the fall in aortic compressing forces, is not known.

Effects of hypertension on vasa vasorum. The increase in arterial pressure during aortic occlusion might be expected to increase flow through vasa vasorum for several reasons. First, an increase in perfusion pressure tends to increase blood flow passively. Second, if vasa vasorum are influenced by neural stimuli, activation of baroreceptors during hypertension would be expected to produce dilation in vasa vasorum. Third, aortic wall tension increases during acute hypertension, as arterial pressure increases (16); if part of the increase in tension is transmitted to the smooth muscle, as well as collagen, metabolic needs of the vessel would increase (17). In other vascular beds, increased metabolism is a potent vasodilator stimulus.

On the other hand, several factors might tend to decrease conductance of vasa vasorum during hypertension. Autoregulation is one such factor. In many vascular beds autoregulation tends to maintain blood flow

\footnotetext{
${ }^{1}$ Armstrong, M. L. Unpublished observations.
} 


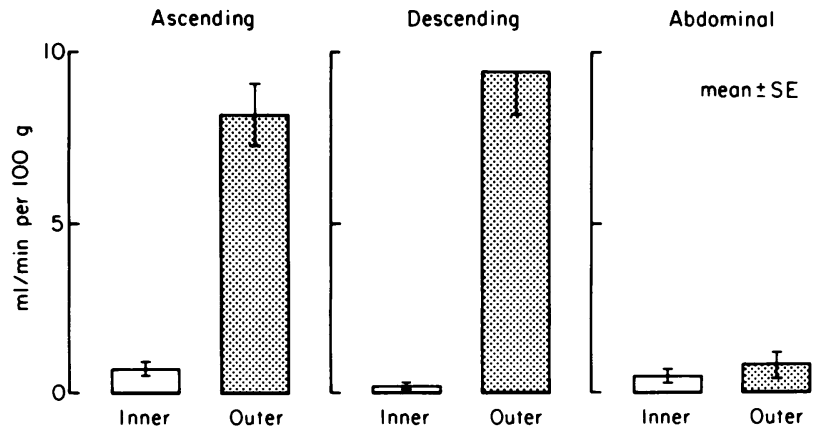

Figure 2 Blood flow to the media of the ascending and descending thoracic aorta and to the abdominal aorta, as summarized from control values in Table IV. The outer layers of the media of the thoracic aorta receive blood flow through vasa vasorum, but the remainder of the aorta receives minimal blood flow.

constant despite changes in arterial pressure. However, it is difficult to attribute the decrease in blood flow through vasa vasorum during hypertension to autoregulation. Autoregulation might minimize an increase in blood flow during hypertension, but it would not be expected to decrease flow significantly.

We speculate that the decrease in conductance of vasa vasorum during hypertension may be the result of distention of the aorta and distortion of vasa vasorum. It would not be necessary for vasa vasorum to be compressed during hypertension to decrease their conductance. Because the cross-sectional area of a vessel is greatest when it is circular, if hypertension distorts vasa vasorum to an ovoid shape, conductance would decrease.

One might expect that, at the same level of hypertension, norepinephrine, because of its direct vasoconstrictor effect, would decrease conductance of vasa vasorum more than aortic occlusion. The observation that the decrease in conductance was less during norepinephrine may be related to three factors: $(a)$ a direct constrictor effect of norepinephrine on vasa vasorum may be small; $(b)$ norepinephrine may constrict the aorta and attenuate the increase in aortic diameter during acute hypertension, thereby reducing distortion of vasa vasorum and the decrease in conductance; $(c)$ norepinephrine may stimulate contraction of smooth muscle in the aorta and produce dilation of vasa vasorum by an indirect effect mediated through increases in metabolism. This effect of norepinephrine on blood flow through vasa vasorum would be analagous to effects of norepinephrine on coronary blood flow.

We might consider the clinical implications of these studies. Wilens et al. (5) reported that medial necrosis of the aorta occurs within several days after ligation of the intercostal arteries which give rise to vasa vasorum. The studies of Wilens et al. raise the possibility that vasa vasorum may be involved in the pathogenesis of aortic medial necrosis and dissecting aneurysm. Wolinsky has demonstrated that despite hypertrophy of the media, aortic wall tension and stress are increased in chronic hypertension in the rat (18). We would speculate that if increased wall tension increases metabolic needs of the aorta and if blood flow through vasa vasorum fails to increase during chronic as well as acute hypertension, this might contribute to ischemia of the aortic wall, medial necrosis, and dissecting aneurysm.

\section{ACKNOWLEDGMENTS}

We thank Peter Preston, Leonard Brooks, Eric Larsen, and Marjorie Megan for technical assistance, Dr. Leon Burmeister for assistance with statistical analyses, Oscar Lim for computer programming, Patti Young for typing the manuscript, and Dr. Allyn Mark for critical review of the manuscript.

This study was supported by Research Career Development awards HL-0004 1 and HL-00328, research grants HL-16066, HL-14230, and HL-20827, Program Project grant HL-14388 from the National Heart and Lung Institute, and by research grant MRIS 3546 from the Veterans Administration.

\section{REFERENCES}

1. Geiringer, E. 1951. Intimal vascularization and atheromatosis. J. Pathol. Bacteriol. 63: 201.

2. Wolinsky, H., and S. Glagov. 1967. Nature of species differences in the medial distribution of aortic vasa vasorum in mammals. Circ. Res. 20: 409-421.

3. Kosan, R. L., and A. C. Burton. 1966. Oxygen consumption of arterial smooth muscle as a function of active tone and passive stretch. Circ. Res. 18: 76.

4. Wolinsky, H., and S. Glagov. 1969. Comparison of abdominal and thoracic aortic medial structure in mammals. Circ. Res. 25: 677-686.

5. Wilens, S. L., J. A. Malcolm, and J. M. Vasquez. 1965. Experimental infarction (medial necrosis) of the dog's aorta. Am. J. Pathol. 47: 685.

6. Nasu, T. 1963. Pathology of pulseless disease. A systematic study and critical review of twenty-one autopsy cases reported in Japan. Angiology. 14: 225-242.

7. Winternitz, M. C., R. M. Thomas, and P. M. LeCompte. 1938. Biology of arteriosclerosis. Charles C. Thomas Publisher. Springfield, Ill. 3-9.

8. Heistad, D. D., M. L. Marcus, J. C. Ehrhardt, and F. M. Abboud. 1976. Effect of stimulation of carotid chemoreceptors on total and regional cerebral blood flow. Circ. Res. 38: 20-25.

9. Marcus, M. L., R. E. Kerber, J. Ehrhardt, and F. M. Abboud. 1974. Three dimensional geometry of acutely ischemic myocardium. Circulation. 52: 254.

10. Rudolph, A. M., and M. A. Heymann. 1967. The circulation of the fetus in utero: methods for studying distribution of blood flow, cardiac output and organ blood flow. Circ. Res. 21: 163-184.

11. Huntsberger, D. V., and P. E. Leaverton. 1970. Statistical inference in the biomedical sciences. Allyn \& Bacon, Inc., Boston, Mass. 190.

12. Heymann, M. A., B. D. Payne, J. I. E. Hoffman, and A. M. Rudolph. 1977. Blood flow measurements with radionuclide labelled particles. Prog. Cardiovasc. Dis. 20: 55-79.

13. Marcus, M. L., D. D. Heistad, J. C. Ehrhardt, and F. M. Abboud. 1976. Total and regional cerebral blood flow measurements with 7-10 $\mu \mathrm{m}, 15 \mu \mathrm{m}, 25 \mu \mathrm{m}$, and $50 \mu \mathrm{m}$ diameter microspheres. J. Appl. Physiol. 40: 501-507. 
14. Utley, J., E. L. Carlson, J. I. E. Hoffman, H. M. Martinez, and G. D. Buckberg. 1974. Total and regional blood flow measurements with $25 \mu \mathrm{m}, 15 \mu \mathrm{m}, 9 \mu \mathrm{m}$, and filtered 1-10 $\mu \mathrm{m}$ diameter microspheres and antipyrine in dogs and sheep. Circ. Res. 34: 391-405.

15. Moss, A. J., P. Samuelson, C. Angell, and S. L. Minken. 1968. Polarographic evaluation of transmural oxygen availability in intact muscular arteries.J. Atheroscler. Res. 8: 803-810.
16. Wolinsky, H., and S. Glagov. 1964. Structural basis for the static mechanical properties of the aortic media. Circ. Res. 14: 400-413.

17. Ganfield, R. A., F. M. Abboud, D. D. Heistad, P. G. Schmid, and A. L. Mark. 1971. Vascular oxygen consumption and the myogenic response to increased wall tension. Circulation. 44(Suppl. 2): 78 (Abstr.)

18. Wolinsky, H. 1970. Response of the rat aortic media to hypertension. Circ. Res. 26: 507-522. 